Current therapies of renal cell carcinoma (RCC), a highly vascularised tumour, mostly rely on anti-angiogenic treatment options. These include tyrosine kinase inhibitors (TKIs) and anti-VEGF monoclonal antibodies. Although these strategies aim at restraining vascularisation to control tumour growth, the effects of such therapies are much wider, as affecting the vessel structure deeply modifies the microenvironment of the tumour mass. The aim of this review is to provide an overview of current knowledge on the global effects of anti-angiogenic treatment, mostly TKIs, on the shaping of the immune component of the RCC microenvironment. The data supporting the modification of immunity by anti-angiogenic therapies are collected to reveal the potential of angiogenesis modulation as a strategy for the adjuvant anti-cancer approach in immunotherapy.

Key words: renal cell carcinoma, an giogenesis, tyrosine kinase inhibitors, vessel normalisation.

Contemp Oncol (Pozn) 2018; 22 (1A): 14-22 DOI: https://doi.org/10.5114/wo.2018.73878

\section{Immune consequences of anti-angiogenic therapy in renal cell carcinoma}

\author{
Klaudia K. Brodaczewska ${ }^{1}$, Cezary Szczylik ${ }^{1,2,3}$, Claudine Kieda ${ }^{1}$
}

${ }^{1}$ Laboratory of Molecular Oncology, Military Institute of Medicine, Warsaw, Poland ${ }^{2}$ European Health Centre, Otwock, Poland

${ }^{3}$ Medical University of Warsaw, Poland

Despite considerable advances in treatments, in most developed countries cancer is the second cause of death, and the occurrence of the disease is rising all over the world [1]. Renal cell carcinoma (RCC) is among the 10 most prevalent cancers, with increasing incidence worldwide. Additionally, it is a disease with a poor prognosis, as up to $30 \%$ of patients present metastases at the time of diagnosis and a further $20 \%$ will develop them despite treatment [2]. This cancer seeds mostly to the lungs, bones, lymph nodes and liver [3], and metastasis is the main cause of high mortality among RCC patients (50\% of patients during 5 years after diagnosis) [4].

\section{Renal cell carcinoma and angiogenesis}

Renal cell carcinoma is considered a highly vascularised cancer, and recent advances in RCC biology have shown that angiogenesis is the key player in pathophysiology of this cancer [5, 6]. 60-80\% of RCC tumours are characterised by a mutation of the vhl gene [7-9]. VHL, von Hippel-Lindau protein [10], is a tumour suppressor crucial for the hypoxia response pathways; it targets for degradation the $\alpha$-subunit of hypoxia-inducible factor $1 \alpha(\mathrm{HIF}-1 \alpha)$ upon normoxic/physioxic conditions. Partial pressure of oxygen $\left(\mathrm{pO}_{2}\right)$ varies in different tissues; the physiological level (physioxia) ranges from $1 \%$ in the skin to $10 \%$ in the kidney, and reaches $13 \%$ in arterial blood, yet is still below oxygen levels in atmospheric air (21\%) [11]. Upon correct, physiological tissue oxygenation and constitutive expression of HIF-1 $\alpha$, the factor is regulated by oxygen-dependent proteolysis. However, when oxygen is lacking (in a hypoxic microenvironment), HIF-1 $\alpha$ is not hydroxylated by prolyl hydroxylases (PHD), and cannot be recognised by active phosphorylated $\mathrm{VHL}(\mathrm{pVHL})$ and targeted for proteolysis, so it is stabilised and accumulates in the cell [12]. Acting as a transcription factor, HIFl $\alpha$ activates the expression of many genes responsible for cell survival in low $\mathrm{pO}_{2}$ and counteracting pathologic hypoxia. These include VEGF (vascular endothelial growth factor; regulator of angiogenesis), EPO (erythropoietin), glucose transporters (responsible for anaerobic glycolysis), TWIST and Matrix metalloproteinases (significant for epithelial-to-mesenchymal transition and metastasis), cadherins and stemcell related markers (Oct4 and Notch) [13]. Increased secretion of VEGF and platelet-derived growth factor (PDGF) by cancer cells in hypoxia induces the formation and rearrangement of the host vasculature, which helps to sustain tumour growth and dissemination. They act as attractants for endothelial cells and induce their migration towards the tumour and subsequent proliferation [14]. Down-stream effects of HIF1 $\alpha$ activation and stabilisation are summarised in Fig. 1.

De-regulation of VHL in RCC tumours have a similar effect; even in the absence of hypoxia, HIF-1 $\alpha$ is not degraded, leading to activation of downstream signalling as described above. Consequently, VHL truncated kidney 


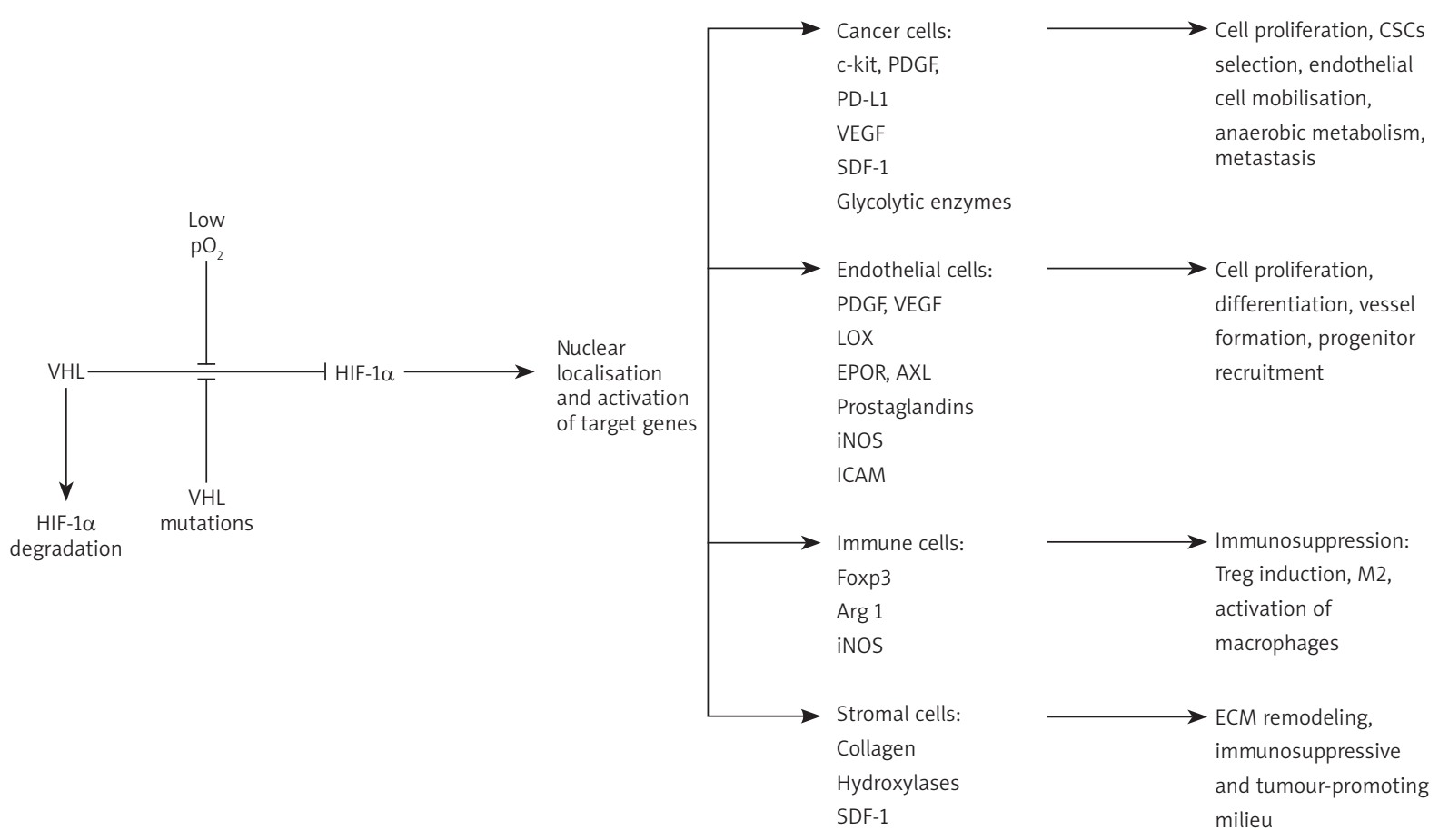

Fig. 1. Downstream effects of HIF1 $\alpha / V H L$ pathway

tumours are characterised by a high level of VEGF [15] and intense angiogenesis [16]. However, blood vessels in the tumour are highly abnormal; they are irregularly shaped and organised, prone to leakage and have disturbed blood flow [17]. In such a setting, the tumour is characterised by temporal and spatial heterogeneity in terms of blood flow, oxygenation and nutrient levels, creating a unique, cancer-promoting microenvironment [18]. Hypoxia, or pseudo-hypoxia related to VHL mutation, was shown to be a selection factor for cancer stem-like cells (CSCs), which are likely to represent the main driving force of cancer progression, relapse and resistance to therapies [19]. Additionally, leaky vessels facilitate cancer spreading; insufficient lining of the endothelium promotes tumour cell extravasation [20]. Additionally, malfunctioning endothelium compromises drug delivery due to incorrect blood perfusion of the tumour mass [21]. On the other hand, pathological vasculature restrains the proper migration of immune cells and the cancer microenvironment activates their suppressive phenotypes [22]. As the tumour microenvironment is now considered as the main driving force for cancer development as well as a potential means to "re-educate" tumour cells [23], pathological angiogenesis seems to be an interesting target for treatment. An indirect strike on the tumour can be sufficient to modify the processes of its growth and progression. Indeed, anti-angiogenic treatments, including tyrosine kinase inhibitors (TKIS), show significant efficacy in the clinic [24]. Many RCC patients benefit from anti-angiogenic therapy [25]; TKI treatment reduces tumour growth and vascular density $[26,27]$ and leads to prolonged survival [28].

\section{Immunosuppression in renal cell carcinoma}

Although RCC is to some extent an immunogenic tumour [29-31], immunosuppression in kidney cancer patients is frequent. The host is unable to develop an adequate immune response and immunity is abrogated by tumour-induced immunosuppression. This is mediated by multiple mechanisms with Treg lymphocytes and myeloid-derived suppressor cells (MDSCs) being the most widely studied in the RCC field.

Although data on Treg frequencies in RCC patients are mixed [32, 33], it was reported that CD4+CD25+Foxp3+ lymphocytes are induced in kidney cancer patients, both in blood and the tumour, which correlates with poor prognosis [33-36], and these cells possess a suppressive phenotype [37]. Kim et al. [38] reported that systemic Treg induction is characteristic for RCC patients with large tumours $(>7 \mathrm{~cm})$, although intra-tumour presence of CD4+CD25+Foxp3+ cells was similar as in healthy kidney tissues. Tregs are important mediators of immunosuppression and mediate toleration to self-antigens in physiological conditions. However, as many cancer antigens are host proteins, activity of Treg cells strongly contributes to cancer immune evasion [39]. Treg cells produce regulatory cytokines, e.g. IL-10 and TGF- $\beta$, and directly influence other leukocytes. Treg cells were shown to hamper maturation of dendritic cells (DCs) (expression of co-stimulatory molecules) and therefore block their activator functions. What is more, Tregs suppress effector T lymphocytes (both CD4+ and CD8+), NK cells and other major players in anticancer immunity [40]. Interestingly, additional expansion of Tregs was observed in RCC patients in response to IL-2 treatment, which explains the weak efficacy of this thera- 
peutic approach [36]. Treg induction in RCC can be a consequence of impaired DC activation [41] and it was shown that other CD4+ cell populations of kidney cancer patients tend to express a naïve/resting phenotype although they do respond to non-specific activation in vitro [42]. In RCC cases it was shown that circulatory Tregs can differ from their intra-tumoural counterparts, which had increased levels of HLA-DR, Fas, and GITR and simultaneously possessed higher suppressive properties [37]. Yet, other studies proved that blood Tregs from RCC cases are functionally suppressive and seem to be more resistant to apoptosis than the cells from healthy individuals [43]. Therefore, restriction of Treg suppressive action seems to be a promising strategy for RCC management, particularly in the case of metastatic disease. Ipilimumab (anti-CTLA-4) and nivolumab (anti-PD-1) are monoclonal antibodies that target Treg-mediated immunosuppression [44]. In mRCC, immunotherapy with these drugs showed significant efficacy in clinical trials and may soon change the treatment paradigm in RCC. According to NCCN guidelines [45], anti-PD-1 antibodies are suggested as a second line treatment for RCC patients treated previously with other drugs; immunotherapy showed superior efficacy to mTOR inhibitor leading to prolonged survival [46]. What is more, anti-PD-1 therapy combined with anti-CTLA-4 antibodies was shown to be more effective first line treatment in comparison to TKIs [47]. This shows emerging role of immunotherapy and immune-modulating therapies for RCC control but also proves crucial role of Treg immunosuppression in the progression of the disease.

Target proteins of anti-CTLA4 and anti-PD-1 antibodies are immune checkpoint receptors and were shown to be negative Treg regulators. CTLA-4 (cytotoxic T-lymphocyte-associated protein 4) is constitutively expressed in these cells and is dependent on Foxp3, a transcription factor that serves as a Treg marker both in mice and humans. CTLA-4 expression is crucial for Treg-mediated protection from autoimmunity; it is postulated that it may be a competitor to CD28 and reduce binding to co-stimulatory molecules on antigen-presenting cells (APCS), suppressing activation of naïve T cells [48]. Anti-CTLA-4 antibodies lead to activation of CD4+ and CD8+ cells regardless of specificity, promoting anti-cancer responses [49]. Also increased diversity of $T$ cell receptors was reported in melanoma patients treated with anti-CTLA-4 antibodies, what may both mediate anti-tumour protection and toxicities. At the same time, anti-CTLA-4 therapy enhanced humoral response to vaccine antigens with no exacerbation of autoimmunity [50]. In cancer, CTLA-4 blockade cause reduction of suppressive T cell activity [51] and activate Th1 cell responses [52]. Programmed cell death-1 (PD-1; CD279) is present on effector T cells, while its ligand (PD-L1) can be found on various cells, including tumour cells. Interactions of these two molecules lead to inhibition of immune responses, both during natural tolerance and cancer immune evasion [53]. Blocking of PD-1/PD-L1 interaction by monoclonal antibodies stops negative signalling and restores T-cell responses; lymphocytes proliferate and produce IFN- $\gamma$ and IL-2 [54]. Cancer-specific CD8+ lymphocytes expand upon PD-1 blockade in melanoma what coincides with in- creased recognition and cytotoxicity against tumour cells [55]. Anti-PD-1 antibodies can modulate the immunological microenvironment in the tumour restoring protective immune responses; $T$ cell infiltration of the tumour can be enhanced [56] with diminished Treg activity [57]. On the other hand, anti-PD-L1 therapy showed only moderate anti-cancer efficacy [58]. Importantly, PD-L1 is regulated by the HIF1 $\alpha$ pathway; it is overexpressed in hypoxia and in VHL-mutated RCC cells [59]. This directly links hypoxia and immunosuppression but also suggests that counteracting low $\mathrm{pO}_{2}$ in tumours is a strategy to shape the anti-cancer immune response. Overall, blockade of CTLA-4 and PD-1 mediated Treg suppression is of great importance in restoring protective responses with proved clinical potential.

MDSCs are another population of cells with suppressive functions observed during RCC. These is a heterogeneous population of progenitors of mono- and granulocytes that are normally present in the bone marrow and blood to serve as a backup pool. However, during pathological states, such as cancer or chronic inflammation, these progenitors fail to mature but become activated and express a suppressive phenotype [60]. MDSCs suppress antigen-specific and non-specific activation of CD4+ and CD8+ lymphocytes in both a direct and indirect manner. $T$ cells are arrested in G0/G1 phase of the cell cycle by depletion of $\mathrm{L}$-arginine and cysteine from the microenvironment by extensive MDSC metabolism of these amino acids [61]. Also, leukocyte migration is affected, leading to reduced infiltration of the tumour with effector cells. Due to antigen-presenting abilities of MDSC, Treg cells can be additionally induced [62]. Production of IL-10 by MDSC further leads to an ineffective response, including M2 (or alternative) activation of macrophages [63]. This cell population is induced in blood and tumours of kidney cancer patients [64-67], and it was also reproduced in a murine model of RCC [68]. MDSCs were shown to accumulate in the tumour predominantly as compared to the healthy kidney tissues in a murine syngeneic model of kidney cancer. Moreover, both intra-tumoural and splenic cells express a suppressive phenotype [68]. The predominant subpopulation of myeloid suppressor cells in RCC patients comprises granulocytic MDSCs with enhanced arginase 1 activity [67]. In mRCC patients, the blood elevation of arginase 1 activity (low L-arginine, high L-ornithine levels) coincided with decreased $\zeta$ chain expression in $T$ and NK cells. As in vitro depletion of MDSCS restores T cell responsiveness to anti-T cell receptor (TCR) stimulation, the suppressive role of these cells in RCC patients is significant [69]. Interestingly, granulocytic MDSCs from RCC were shown to be more resistant to apoptosis after activation in comparison to cells from healthy individuals [67], but they are susceptible to cell death mediated by IL-2/anti-CD40 treatment [70]. The ways in which RCC activates MDSCs are not yet elucidated; however, most likely they are induced by secretion of GM-CSF, M-CSF, IL-6, IL-10, TGF- $\beta$, COX-2 or PGE2, as shown for other cancers [61, 71]. Also VEGF blocks myeloid cell maturation, which may account for RCC induction of MDSCs [72]. High mobility group box-1 protein (HMGB1) expression in the tumour was linked with suppression by myeloid cells in RCC; blocking of the protein reduced the 
progression of the disease by inhibition of MDSC induction [73].

Currently, studies performed on targeting MDSCs focus mainly on limiting their suppressive functions. PDE-5 inhibitors were shown to limit MDSC suppression in cancer by inhibition of arginase 1 and iNOS - enzymes whose activity mediates T cell suppression [74]. Also COX-2 inhibitors can be used to block PGE-2 production, which is responsible for MDSC expansion [75]. In RCC, another approach was also used: administration of retinoic acid in cancer patients, which led to differentiation of MDSCs and abrogated their suppressive phenotype $[76,77]$. However, no immunotherapy based on direct counteracting MDSCS is currently used in the clinic on daily basis [78].

Additionally, RCC cells counteract protective immune responses directly by secretion of suppressive cytokines or expression of down-regulating receptors. Lymphocyte apoptosis induced by RCC cells through CD70 [79] or FasL mediated mechanisms [80] and the lack of co-activation molecules (B7-1 and B7-2) [81] contributes to ineffective immunity in kidney cancer patients. Mutation of $v h l$ in RCC cells was also shown to reduce interactions of cancer and immune cells in a VCAM-mediated mechanism [82]. Immune escape is also related to disturbed antigen processing and presentation by cancer and APCs [83-86]. HLA-G, a non-classical MHC class I molecule, is frequently up-regulated in RCC [87], and this receptor protects cancer cells from recognition by immune cells and subsequently lysis [88]. Also IL-6, IL-10, TNF, TGF and VEGF secreted by RCC cells create a cytokine milieu that down-regulates immunity [89-91]. A non-protective response in RCC is also related to unfavourable immune bias - non-protective Th2 and Th17 tend to be elevated during kidney cancer [92], which is mediated, among other factors, by impaired DC activation [93].

Although limitation of tumour-induced immunosuppression seems to be a promising approach to treat cancer [94], immunotherapy is rarely treated as a single option [95]. Cancer is a complicated disease and it has to be addressed on multiple levels, as breaching subtle tumour-host interactions can lead to far-reaching consequences. Immunotherapy, like any other drug treatment, is limited by the accessibility of the tumour site where the cells to counteract are located. Changing the conditions of the vasculature by restraining the anarchic growth of inefficient vessels would help to obtain a properly functioning vascular network. This is a purpose of TKI treatment, which may change the tumour microenvironment and influence immune responses of the host and immunomodulatory action of the cancer cells. Therefore, this aspect of anti-angiogenic therapy can serve as a strategy to boost natural defence mechanisms of the host.

\section{Anti-angiogenic therapy of renal cell carcinoma and changes in the immune response}

When diagnosed early, over $50 \%$ of RCC patients are cured, but late stage disease has a poor prognosis. In the case of primary RCC, partial or radical nephrectomy without adjuvant therapy is a preferred treatment. With disease progression, apart from resection of metastatic tumours, systemic therapy is implemented. Since 2005 targeted therapy is possible for advanced RCC, which up to now consists of 7 FDA-approved drugs, including: tyrosine kinase inhibitors (TKIs; sunitinib, sorafenib, pazopanib, axitinib), mTOR inhibitors (temsirolimus, everolimus), anti-VEGF antibodies and immunotherapy, as described earlier in this review. Additionally, combinational therapy and other targeted drugs, like cabozantinib, reported efficient in different cancers, are tested as second line treatment in $\mathrm{mRCC}$ patients relapsing after prior treatment $[45,96]$. VEGF and many other growth factors bind to their receptors that contain tyrosine kinases in the intracellular domain that is responsible for transduction of the signal inside the cell [97]. Tyrosine kinase inhibitors are small molecules that target these intracellular domains of receptor and in-cell signalling molecules [98]. Drugs that are currently used in anti-RCC treatment and slightly differ in specificity, include sorafenib (targeting VEGFR-2, VEGFR-3), sunitinib (targeting VEGFR 1-3, PDGFR, KIT, FLT3), pazopanib (targeting VEGFR, PDGFR, KIT) and axitinib (targeting VEGFR 1-3, PDGFR, KIT) [99]. All these TKIs showed benefit in $\mathrm{mRCC}$ patients [100]. Despite the relatively large amount of data on TKI effectiveness in different patient groups [101-114] there are surprisingly few studies on the molecular effects of this treatment on the RCC tumour and its microenvironment.

Anti-angiogenic therapy shows a wide spectrum of effects. TKIs directly reduce tumour growth by inhibition of c-kit signalling in cancer cells of c-kit and PDGF signalling, thus regulating their proliferation [115]. At the same time, TKIs target endothelial cells by inhibition of VEGF signalling, which is crucial for recruitment of new vessels and modulates tumour vascularisation [116]. This restrains tumour expansion; its growth is tempered and angiogenesis is normalised. Blocked receptors fail to activate endothelial cells to form new vasculature in the tumour but also restore proper functions of existing cancer-induced blood vessels. Also, as a consequence of TKI treatment, tumour compactness is diminished, leading to better perfusion [116]. TKIs should then normalise the tumour microenvironment, leading to homogeneous conditions in the tumour, and reduce expression of growth factors, which may cause partial control of the disease. Additionally, TKI-mediated modification of cancer cells and angiogenesis affects the immune microenvironment; cancer-induced immunosuppression can be reversed, restoring host immunity [116]. When normal functions of blood vessels are regained, the tumour mass is again available for the action of immune cells [117] and other drugs when applied as adjuvant treatment [17]. As an example, it was observed that in cancer patients treated with TKIs, induction of immunosuppressive cell populations is reduced in comparison to untreated controls, which proves the additional benefit of anti-angiogenic treatment and makes it an adjuvant strategy for immunotherapy. Although the mechanism of this phenomenon is also weakly described, changes in the tumour microenvironment affect its immunogenic/immunomodulatory abilities.

TKls were shown to directly affect T cell functions, decreasing proliferation and inducing apoptosis [118], yet this study was performed on effector $T$ cells and it is not certain that a simi- 
Table 1. Immunosuppression mechanisms induced by RCC and affected by TKI treatment

\begin{tabular}{lll}
$\begin{array}{l}\text { Immunosuppressive } \\
\text { mechanism }\end{array}$ & Observation in RCC patients & Effect TKI \\
\hline $\begin{array}{l}\text { Treg induction } \\
\text { Increased percentage in blood [33, 36, 38, 121] }\end{array}$ & $\begin{array}{l}\text { Reduced percentage [66, 119, 132] } \\
\text { Increased percentage [131] } \\
\text { Local accumulation in tumour [33] } \\
\text { Unchanged accumulation [38] }\end{array}$ & Reduced infiltration [120, 130] \\
\hline MDSC induction & Increased percentage in blood [64-67] & Reduced percentage [66] \\
\hline Th1/Th2 polarisation & Local accumulation in tumour [64-67] & Reduced infiltration [122]
\end{tabular}

lar effect is valid for Treg cells - especially as in vivo, TKI were shown to increase $T$ cell mediated immunity in other cancers [116]. Sunitinib decreased the amount of circulatory [66, 119] and intra-tumoural Treg lymphocytes in RCC [120]. It was also observed to modulate Th2 immune bias and promote Th1-related responses [119] while decreasing regulatory cells [121]. Also the percentage of MDSCs in the blood of RCC patients dropped after 28 days of sunitinib therapy with a simultaneous increase in IFN- $\gamma$ production in T cells [66]. In a murine model of kidney cancer it was confirmed that also intratumoural and splenic accumulation of MDSCs is reduced by sunitinib, and initial observations suggest that a similar phenomenon occurs in humans [122]. It can be mediated by Stat3 dependent inhibition of pro-angiogenic activity of MDSCs [123]. As VEGF receptors are expressed by MDSCs [124], a direct effect of TKIs on these cells is possible. Sunitinib was shown to impair proliferation and survival of MDSCs in murine cancer. However, similarly to tumour cells, this cell population may become resistant to TKIs [125]. Normal type DC distribution was recovered in RCC patients after sunitinib administration [126]. TKI therapy improved tumour infiltration with CD8+ cells [127] and increased T cell functions measured by the level of IFN [122], which supports the use of sunitinib in combination with immunotherapy.

Sorafenib's effect on the immune response in RCC is much less clear. The drug was reported to alter DC maturation, impairing $T$ cell responses $[128,129]$. Nonetheless, sorafenib treatment reduced the infiltration of the tumour with Treg cells [130] while others showed that this TKI augments Foxp3+ lymphocytes in peripheral blood [131]. Busse et al. [132] on the other hand observed diminished percentages of circulatory Tregs in sorafenib-treated RCC patients but no effect of the therapy could be seen on the level IL-10 or TGF $\beta$.

The systemic up-regulation of immunity during anti-angiogenic treatment of RCC is additionally striking, as TKIs were shown to have direct immunosuppressive properties ([133] for review). This suggests the predominance of the vessel normalisation effect on the overall microenvironment and disease progression. Moreover, another approach for anti-angiogenic therapy using anti-VEGF antibodies showed no effect on the development of immunosuppression as MDSCs were not affected by the treatment [67], proving the importance of the definition of the term anti-angiogenic strategies.

\section{Conclusions}

Although the nature of immunosuppression reversal observed in TKI-treated RCC patients cannot be fully ex- plained, it seems that the drugs affect immune cells both directly, inhibiting tyrosine kinase pathways, and indirectly. This has deep consequences by modification of the malignant microenvironment. Overall, treatment with TKIs is one of the anti-angiogenic strategies because, by modifying endothelial cell growth, they reduce the anarchic angiogenesis and cause restoration of functional vasculature in the tumour. This leads to normalised $\mathrm{pO}_{2}$ and improves cell metabolism, while phenotypically normalised endothelium regulates the functions of vessels. This enhances the efficacy of chemotherapeutics, radiotherapy and migration of immune cells. Nevertheless, the normalisation effect of TKIs is transient, and temporal TKI resistance in RCC is often observed $[26,134]$; ultimately anti-angiogenic therapy leads to vascular regression and consequently hypoxia with all its cancer-promoting mechanisms [135]. Therefore, an innovative approach for the control of cancer growth could be persistent and stable vessel normalisation [136]. This could be achieved by several means, including enhanced $\mathrm{O}_{2}$ transport by erythrocytes and/or targeted reduction of pro-angiogenic signals. Kieda et al. showed that administration of the allosteric haemoglobin effector myo-inositol-trispyrophosphate (ITPP) increases the oxygen level and blood flow in experimental settings of melanoma and breast cancer models [137, 138]. ITPP caused activation of PTEN in endothelial cells, which led to vessel repair, and the treatment caused suppression of $H I F 1 \alpha$-activated pathways and reduced the pro-angiogenic activity of the tumours. These results suggest that ITPP can be an interesting adjuvant molecule improving the vascular architecture and enhancing the efficacy of co-administered drugs. Additionally, the same group described a novel anti-VEGF therapy using epithelial precursor cells (EPCS) - tissue-specific cells which express soluble VEGF-R, consuming the excess VEGF [139]. SVEGF-R is under the control of the hypoxia response element (HRE) and thus is expressed only in hypoxic conditions. When the vessels are normalised, hypoxia is alleviated and the sVEGF-R is no longer produced. Such an approach also causes stable vessel normalisation and is tightly controlled by the treatment outcome. Re-organisation of the tumour epithelium results in proper vasculature that can mediate immune infiltration, hypoxia alleviation and drug transport. These and other strategies can potentially be an adjuvant strategy to RCC treatment. Stable normalisation of the tumour vasculature can be effective in restoration of the protective immune response, as seen in TKI-treated RCC patients, yet long-term effectiveness of the novel approach can be 
more beneficial for patients, leading to prolonged control of the disease.

KKB and CS were supported by Military Institute of Medicine intramural grant no. 1/8910(414). CK was supported by the Ministry of Defence grant Kosciuszko I no. 579/2016/DA. The authors declare no conflicts of interest.

\section{References}

1. Siegel RL, Miller KD, Jemal A. Cancer statistics, 2016. CA: A Cancer Journal for Clinicians 2016; 66: 7-30.

2. Ljungberg B, Campbell SC, Choi HY, et al. The epidemiology of renal cell carcinoma. Eur Urol 2011; 60: 615-21.

3. Bianchi M, Sun M, Jeldres C, et al. Distribution of metastatic sites in renal cell carcinoma: a population-based analysis. Ann Oncol 2012; 23: 973-80.

4. Cho E, Adami H-O, Lindblad P. Epidemiology of renal cell cancer. Hematol Oncol Clin North Am 2011; 25: 651-65.

5. Hélénon O, Eiss D, Debrito P, Merran S, Correas JM. How to characterise a solid renal mass: A new classification proposal for a simplified approach. Diagn Interv Imaging 2012; 93: 232-45.

6. Arjumand W, Sultana S. Role of VHL gene mutation in human renal cell carcinoma. Tumor Biol 2012; 33: 9-16.

7. Cowey CL, Rathmell WK. VHL gene mutations in renal cell carcinoma: Role as a biomarker of disease outcome and drug efficacy. Curr Oncol Rep 2009; 11: 94-101.

8. van Houwelingen KP, van Dijk BA, Hulsbergen-van de Kaa CA, et al. Prevalence of von Hippel-Lindau gene mutations in sporadic renal cell carcinoma: results from the Netherlands cohort study. BMC Cancer 2005; 5: 57.

9. Nickerson ML, Jaeger E, Shi Y, et al. Improved Identification of von Hippel-Lindau Gene Alterations in Clear Cell Renal Tumors. Clin Cancer Res 2008; 14: 4726-34.

10. Latif F, Tory K, Gnarra J, et al. Identification of the von Hippel-Lindau disease tumor suppressor gene. Science 1993; 260: 1317-20.

11. Carreau A, El Hafny-Rahbi B, Matejuk A, Grillon C, Kieda C. Why is the partial oxygen pressure of human tissues a crucial parameter? Small molecules and hypoxia. J Cell Mol Med 2011; 15: 123953.

12. Kapitsinou P, Haase V. The VHL tumor suppressor and HIF: insights from genetic studies in mice. Cell Death Differ 2008; 15: 650-9.

13. Liu W, Shen SM, Zhao XY, Chen Dr. GQ. Targeted genes and interacting proteins of hypoxia inducible factor-1. Int I Biochem Mol Biol 2012; 3: 165-78.

14. Hoeben A. Vascular Endothelial Growth Factor and Angiogenesis. Pharmacological Reviews 2004; 56: 549-80.

15. Takahashi A, Sasaki H, Kim SJ, et al. Markedly increased amounts of messenger RNAs for vascular endothelial growth factor and placenta growth factor in renal cell carcinoma associated with angiogenesis. Cancer Res 1994; 54: 4233-7.

16. De S, Dey YN, Sarkar P, Gaidhani S. An overview of angiogenesis and renal cell carcinoma Introduction. Int I NutrPharm Neurol Dis 2012; 2: 3-7.

17. Goel S, Duda DG, Xu L, et al. Normalization of the vasculature for treatment of cancer and other diseases. Physiol Rev 2011; 91: 1071-121.

18. Nagy JA, Chang S-H, Dvorak AM, Dvorak HF. Why are tumour blood vessels abnormal and why is it important to know? $\mathrm{Br}$ J Cancer 2009; 100: 865-9.

19. Carnero A, Lleonart M. The hypoxic microenvironment: A determinant of cancer stem cell evolution. Inside the Cell 2016; 1: 96-105.

20. McCarthy N. Metastasis: Leaky effect. Nat Rev Cancer 2012; 12: 157.

21. Azzi S, Hebda JK, Gavard J. Vascular permeability and drug delivery in cancers. Front Oncol 2013; 3: 211.
22. Allegrezza MJ, Conejo-Garcia JR. Targeted Therapy and Immunosuppression in the Tumor Microenvironment. Trends Cancer 2017; 3: 19-27.

23. Quail DF, Joyce JA. Microenvironmental regulation of tumor progression and metastasis. Nat Med 2013; 19: 1423-37.

24. El-Kenawi AE, El-Remessy AB. Angiogenesis inhibitors in cancer therapy: mechanistic perspective on classification and treatment rationales. Br J Pharmacol 2013; 170: 712-29.

25. Rini BI. VEGF-targeted therapy in metastatic renal cell carcinoma. Oncologist 2005; 10: 191-7.

26. Oosterwijk-Wakka JC, Kats-Ugurlu G, Leenders WP, et al. Effect of tyrosine kinase inhibitor treatment of renal cell carcinoma on the accumulation of carbonic anhydrase IX-specific chimeric monoclonal antibody cG250. BJU International 2011; 107: 118-25.

27. Larkin J, Esser N, Calvo E, et al. Efficacy of sequential treatment with sunitinib-everolimus in an orthotopic mouse model of renal cell carcinoma. Anticancer Res 2012; 32: 2399-2406.

28. Escudier B, Eisen T, Stadler WM, et al. Sorafenib in advanced clear-cell renal-cell carcinoma. N Engl J Med 2007; 356: 125-34.

29. Jantzer P, Schendel DJ. Human renal cell carcinoma antigen-specific CTLs: antigen-driven selection and long-term persistence in vivo. Cancer Res 1998; 58: 3078-86.

30. Magyarlaki T, Mosolits S, Baranyay F, Buzogány I. Immunohistochemistry of complement response on human renal cell carcinoma biopsies. Tumori 1996; 82: 473-79.

31. Janiszewska AD, Poletajew S, Wasiutyński A. Spontaneous regression of renal cell carcinoma. Contemp Oncol (Pozn) 2013; 17: 123-27.

32. Finke JH, Rini B, Ireland J, et al. Sunitinib reverses type-1 immune suppression and decreases T-regulatory cells in renal cell carcinoma patients. Clin Cancer Res 2008; 14: 6674-82.

33. Liotta F, Gacci M, Frosali F, et al. Frequency of regulatory T cells in peripheral blood and in tumour-infiltrating lymphocytes correlates with poor prognosis in renal cell carcinoma. BJU Int 2011; 107: 1500-6.

34. Griffiths RW, Elkord E, Gilham DE, Ramani V, Clarke N, Stern PL, Hawkins RE. Frequency of regulatory $T$ cells in renal cell carcinoma patients and investigation of correlation with survival. Cancer Immunol Immunother 2007; 56: 1743-53.

35. Kang MJ, Kim KM, Bae JS et al. Tumor-infiltrating PD1-positive lymphocytes and FoxP3-positive regulatory t cells predict distant metastatic relapse and survival of clear cell renal cell carcinoma. Transl Oncol 2013; 6: 282-9.

36. Cesana GC, DeRaffele G, Cohen $S$ et al. Characterization of $\mathrm{CD} 4+\mathrm{CD} 25+$ regulatory $\mathrm{T}$ cells in patients treated with high-dose interleukin-2 for metastatic melanoma or renal cell carcinoma. J Clin Oncol 2006; 24: 1169-77.

37. Asma G, Amal G, Raja M, et al. Comparison of circulating and intratumoral regulatory $T$ cells in patients with renal cell carcinoma. Tumor Biol 2015; 36: 3727-34.

38. Kim CS, Kim Y, Kwon T, et al. Regulatory T cells and TGF- $\beta 1$ in clinically localized renal cell carcinoma: Comparison with agematched healthy controls. Urol Oncol 2015; 33: 113.e19-25.

39. Vieweg J, Su Z, Dahm P, Kusmartsev S. Reversal of tumor-mediated immunosuppression. Clin Cancer Res 2007; 13: 727s-32s.

40. Finke JH, Rayman Pa, Ko JS, Bradley JM, Gendler SJ, Cohen PA. Modification of the tumor microenvironment as a novel target of renal cell carcinoma therapeutics. Cancer J 2013; 19: 353-64.

41. Teng L, Chen Y, Ding D, Dai H, Liu G, Li C. Immunosuppressive effect of renal cell carcinoma on phenotype and function of dendritic cells. Int Urol Nephrol 2014; 46: 915-20.

42. Dannull J, Su Z, Rizzieri D et al. Enhancement of vaccine-mediated antitumor immunity in cancer patients after depletion of regulatory T cells. J Clin Investi 2005; 115: 3623-33.

43. Jeron A, Pfoertner S, Bruder D Geffers R, Hammerer P, Hofmann $R$, Buer J, Schrader AJ.. Frequency and gene expression profile of regulatory T cells in renal cell carcinoma. Tumour Biol 2009; 30: 160-70.

44. Callahan MK, Wolchok JD. At the bedside: CTLA-4- and PD-1blocking antibodies in cancer immunotherapy. J Leukoc Biol 2013; 94: 41-53.

45. Motzer RJ, Jonasch E, Agarwal N, et al. Kidney Cancer, Version 2.2017, NCCN J Natl Compr Canc Netw 2017; 15: 804-34. 
46. Motzer RJ, Escudier B, McDermott DF, et al. Nivolumab versus Everolimus in Advanced Renal-Cell Carcinoma. N Engl J Med 2015; 373: 1803-13.

47. Hammers HJ, Plimack ER, Sternberg C, et al. CheckMate 214: A phase III, randomized, open-label study of nivolumab combined with ipilimumab versus sunitinib monotherapy in patients with previously untreated metastatic renal cell carcinoma. http://dx. doi.org/10.1200/jco.2015.33.15 suppl.tps4578 2017.

48. Tai X, Van Laethem Fo, Pobezinsky L, et al. Basis of CTLA-4 function in regulatory and conventional CD4 + T cells. Blood 2012; 119 5155-63.

49. Wolchok JD, Saenger Y. The mechanism of anti-CTLA-4 activity and the negative regulation of T-cell activation. Oncologist 2008 13 Suppl 4: 2-9.

50. Keler T, Halk E, Vitale L, et al. Activity and safety of CTLA-4 block ade combined with vaccines in cynomolgus macaques. J Immu nol 2003; 171: 6251-9.

51. Hannani D, Vetizou M, Enot D, et al. Anticancer immunotherapy by CTLA-4 blockade: obligatory contribution of IL-2 receptors and negative prognostic impact of soluble CD25. Cell Res 2015; 25 208-24.

52. Wei SC, Levine JH, Cogdill AP, et al. Distinct Cellular Mechanisms Underlie Anti-CTLA-4 and Anti-PD-1 Checkpoint Blockade. Cell 2017; 170: 1120-33.e1117.

53. Francisco LM, Sage PT, Sharpe AH. The PD-1 pathway in tolerance and autoimmunity. Immunol Rev 2010; 236: 219-42.

54. Wang C, Thudium KB, Han M, et al. In vitro characterization of the anti-PD-1 antibody nivolumab, BMS-936558, and in vivo toxicology in non-human primates. Cancer Immunol Res 2014; 2: 846-56.

55. Wong RM, Scotland RR, Lau RL, et al. Programmed death-1 block ade enhances expansion and functional capacity of human melanoma antigen-specific CTLs. Int Immunol 2007; 19: 1223-34.

56. Immune Checkpoint Blockade to Improve Tumor Infiltrating Lym phocytes for Adoptive Cell Therapy. 2017.

57. Dyck L, Wilk MM, Raverdeau M, et al. Anti-PD-1 inhibits Foxp3(+) Treg cell conversion and unleashes intratumoural effector T cells thereby enhancing the efficacy of a cancer vaccine in a mouse model. Cancer Immunol Immunother 2016; 65: 1491-8.

58. McDermott DF, Kluger HF, Sosman JA, et al. Immune correlates and long-term follow-up of a Phase la study of MPDL3280A, an engineered PD-L1 antibody, in patients with metastatic renal cell carcinoma (mRCC). Ann Oncol 2017; 25 suppl.

59. Messai Y, Gad S, Noman MZ, et al. Renal cell carcinoma programmed death-ligand 1, a new direct target of hypoxia-inducible factor-2 alpha, is regulated by von Hippel-Lindau gene mutation status. Eur Urol 2016; 70: 623-32.

60. Gabrilovich DI, Nagaraj S. Myeloid-derived suppressor cells as regulators of the immune system. Nat Rev Immunol 2009; 9: 162 74.

61. Sevko A, Umansky V. Myeloid-derived suppressor cells interact with tumors in terms of myelopoiesis, tumorigenesis and immunosuppression: thick as thieves. J Cancer 2013; 4: 3-11.

62. Serafini P, Mgebroff S, Noonan K, Borrello I. Myeloid-derived suppressor cells promote cross-tolerance in B-cell lymphoma by ex panding regulatory T cells. Cancer Res 2008; 68: 5439-49.

63. Najjar YG, Finke JH. Clinical perspectives on targeting of myeloid derived suppressor cells in the treatment of cancer. Front Oncol 2013; 3: 49.

64. Najjar YG, Rayman PA, Tannenbaum C et al. Accumulation of MDSC subsets in renal cell carcinoma correlates with grade and progression free survival, and is associated with intratumoral expression of IL-1ß, IL-8 and CXCL5. J Immunother Cancer 2014; 2: P227.

65. Brandau S, Trellakis S, Bruderek K, et al. Myeloid-derived suppressor cells in the peripheral blood of cancer patients contain a subset of immature neutrophils with impaired migratory properties. Leukoc Biol 2011; 89: 311-7.

66. Ko JS, Zea AH, Rini BI, et al. Sunitinib mediates reversal of myeloid-derived suppressor cell accumulation in renal cell carcinoma patients. Clin Cancer Res2009; 15: 2148-57.

67. Rodriguez PC, Ernstoff MS, Hernandez C, Atkins M, Zabaleta J, Sierra R, Ochoa AC. Arginase I-producing myeloid-derived suppres- sor cells in renal cell carcinoma are a subpopulation of activated granulocytes. Cancer Res 2009; 69: 1553-60.

68. James BR, Anderson KG, Brincks EL, Kucaba TA, Norian LA, Masopust D, Griffith TS. CpG-mediated modulation of MDSC contributes to the efficacy of Ad5-TRAIL therapy against renal cell carcinoma. Cancer Immunol Immunother 2014; 63: 1213-27.

69. Ochoa AC, Zea AH, Hernandez C, Rodriguez PC. Arginase, prostaglandins, and myeloid-derived suppressor cells in renal cell carcinoma. Clin Cancer Res 2007; 13(2 Pt 2): 721s-6s.

70. Weiss JM, Subleski JJ, Back T et al. Regulatory T cells and my eloid-derived suppressor cells in the tumor microenvironment undergo Fas-dependent cell death during IL-2/aCD40 therapy. J Immunol 2014; 192: 5821-9.

71. Yamada D, Matsushita H, Azuma T, et al. Granulocyte macrophage colony-stimulating factor as a predictor of the response of metastatic renal cell carcinoma to tyrosine kinase inhibitor therapy. Mol Clin Oncol 2014; 2: 1023-7.

72. Gabrilovich DI, Chen HL, Girgis KR, et al. Production of vascular endothelial growth factor by human tumors inhibits the functional maturation of dendritic cells. Nat Med 1996; 2: 1096-103.

73. Li J, Sun J, Rong R, Li L, Shang W, Song D, Feng G, Luo F. HMGB1 promotes myeloid-derived suppressor cells and renal cell carcinoma immune escape. Oncotarget 2017; 8: 63290-8.

74. Serafini P, Meckel K, Kelso M, et al. Phosphodiesterase-5 inhibition augments endogenous antitumor immunity by reducing myeloid-derived suppressor cell function. J Exp Med 2006; 203: 2691-702.

75. Sinha P, Clements VK, Fulton AM, Ostrand-Rosenberg S. Prosta glandin E2 promotes tumor progression by inducing myeloid-derived suppressor cells. Cancer Res 2007; 67: 4507-13.

76. Kusmartsev S, Eruslanov E, Kübler H, et al. Oxidative stress regulates expression of VEGFR1 in myeloid cells: link to tumor-induced immune suppression in renal cell carcinoma. J Immunol 2008; 181: 346-53.

77. Kusmartsev S, Su Z, Heiser A, et al. Reversal of myeloid cell-mediated immunosuppression in patients with metastatic renal cell carcinoma. Clin Cancer Res 2008; 14: 8270-8.

78. Albeituni SH, Ding C, Yan J. Hampering immune suppressors: therapeutic targeting of myeloid-derived suppressor cells in cancer. Cancer J 2013; 19: 490-501.

79. Diegmann J, Junker K, Loncarevic IF, Michel S, Schimmel B, von Eggeling F. Immune escape for renal cell carcinoma: CD70 mediates apoptosis in lymphocytes. Neoplasia 2006; 8: 933-8.

80. Uzzo RG, Rayman P, Kolenko V, et al. Mechanisms of apoptosis in T cells from patients with renal cell carcinoma. Clin Cancer Res1999; 5: 1219-29.

81. Jung D, Hilmes C, Knuth A, Jaeger E, Huber C, Seliger B. Gene transfer of the Co-stimulatory molecules B7-1 and B7-2 enhances the immunogenicity of human renal cell carcinoma to a different extent. Scand I Immunol 1999; 50: 242-9.

82. Labrousse-Arias D, Martínez-Alonso E, Corral-Escariz M, et al. VHL promotes immune response against renal cell carcinoma via NF-кB-dependent regulation of VCAM-1. J Cell Biol 2017; 216: 835-47.

83. Hodson I, Bock M, Ritz U, et al. International journal of oncology. Int J Oncol 2003; 23: 991-9.

84. Seliger B, Atkins D, Bock M, et al. Characterization of human lymphocyte antigen class I antigen-processing machinery defects in renal cell carcinoma lesions with special emphasis on transporter-associated with antigen-processing down-regulation. Clin Cancer Res 2003; 9.

85. Cabillic F, Bouet-Toussaint F, Toutirais O, et al. Interleukin-6 and vascular endothelial growth factor release by renal cell carcinoma cells impedes lymphocyte-dendritic cell cross-talk. Clin Exp Immunol 2006; 146: 518-23.

86. Schwaab T, Schned AR, Heaney JA, et al. In vivo description of dendritic cells in human renal cell carcinoma. J Urol 1999; 162: 567-73.

87. Li B-L, Lin A, Zhang XJ, et al. Characterization of HLA-G expression in renal cell carcinoma. Tissue Antigens 2009; 74: 213-21.

88. Bukur J, Seliger B. The role of HLA-G for protection of human renal cell-carcinoma cells from immune-mediated lysis: implications for immunotherapies. Semin Cancer Biol 2003; 13: 353-9. 
89. Figel A-M, Brech D, Prinz PU, et al. Human Renal Cell Carcinoma Induces a Dendritic Cell Subset That Uses T-Cell Crosstalk for Tumor-Permissive Milieu Alterations. Am J Pathol 2011; 179: 436-51.

90. Lahn M, Fisch P, Köhler G, et al. Pro-inflammatory and T cell inhibitory cytokines are secreted at high levels in tumor cell cultures of human renal cell carcinoma. Eur Urol 1999; 35: 70-80.

91. Sievers E, Dreimuller P, Haferkamp A, Schmidt-Wolf IG, Buchler MW, Schmidt J, Marten A. Characterization of primary renal carcinoma cultures. Urol Int 2007; 79: 235-43

92. Li L, Yang C, Zhao Z, et al. Skewed T-helper (Th)1/2- and Th17/T regulatorycell balances in patients with renal cell carcinoma. Mol Med Rep 2015; 11: 947-53.

93. Hou MM, Wen-Cheng Chang J, Pang ST, et al. Characterization of the Response of Dendritic Cells and Regulatory T Cells to Tumor Antigens in Patients with Renal Cell Carcinoma. Chang Gung Med 2010; 33: 25-35.

94. Bersanelli M, Buti S. From targeting the tumor to targeting the immune system: Transversal challenges in oncology with the inhibition of the PD-1/PD-L1 axis. World J Clin Oncol 2017; 8: 37-53.

95. Drake CG. Combination immunotherapy approaches. Annals of Oncology 2012; 23: viii41-46.

96. Escudier B, Eisen T, Porta C et al. Renal cell carcinoma: ESMO clinical practice guidelines for diagnosis, treatment and follow-up. Ann Oncol 2012; 23: vii65-71.

97. Shibuya M. Vascular Endothelial Growth Factor (VEGF) and Its Receptor (VEGFR) Signalling in Angiogenesis: A Crucial Target for Anti- and Pro-Angiogenic Therapies. Genes Cancer 2011; 2: $1097-$ 105.

98. Gotink KJ, Verheul HM. Anti-angiogenic tyrosine kinase inhibitors: what is their mechanism of action? Angiogenesis 2010; 13: 1-14.

99. Eckstein N, Röper L, Haas B et al. Clinical pharmacology of tyro sine kinase inhibitors becoming generic drugs: the regulatory perspective. J Exp Clin Cancer Res 2014; 33:15. doi: 10.1186/1756 9966-33-15.

100. Motzer RJ, Figlin Ra, Bukowski RM. Renal Cell Carcinoma: Molecular Targets and Clinical Applications. 2015; 27: 613

101. Joshi A, Ramaswamy A, Noronha $V$ et al. Efficacy and safety of sorafenib in advanced renal cell cancer and validation of Heng criteria. Indian J Cancer 2016; 53: 423-8.

102. Rao A, Lauer R. Phase II study of sorafenib and bortezomib for first-line treatment of metastatic or unresectable renal cell carci noma. Oncologist 2015; 20: 370-1.

103. Escudier B, Michaelson MD, Motzer RJ et al. Axitinib versus sorafenib in advanced renal cell carcinoma: subanalyses by prior therapy from a randomised phase III trial. Br J Cancer 2014; 110: 2821-8.

104. Tafreshi A, Thientosapol E, Liew MS et al. Efficacy of sorafenib in advanced renal cell carcinoma independent of prior treatment, histology or prognostic group. Asia Pac J Clin Oncol 2014; 10: 60-5.

105. Zhao J, Zhu Y, Zhang C, et al. Sorafenib or sunitinib as postoperative adjuvant therapy for Chinese patients with locally advanced clear cell renal cell carcinoma at high risk for disease recurrence. Urol Oncol 2013; 31: 1800-5.

106. Motzer RJ, Nosov D, Eisen T, et al. Tivozanib versus sorafenib as initial targeted therapy for patients with metastatic renal cell carcinoma: results from a phase III trial. J Clin Oncol 2013; 31: 3791-9.

107. Ravaud A, Oudard S, De Fromont $M$, et al. First-line treatment with sunitinib for type 1 and type 2 locally advanced or metastatic papillary renal cell carcinoma: a phase II study (SUPAP) by the French Genitourinary Group (GETUG)dagger. Ann Oncol 2015; 26: $1123-8$.

108. Choueiri TK, Figueroa DJ, Fay AP, et al. Correlation of PD-L1 tumor expression and treatment outcomes in patients with renal cell carcinoma receiving sunitinib or pazopanib: results from COMPARZ, a randomized controlled trial. Clin Cancer Res 2015; 21: 1071-7.

109. Lane BR, Derweesh IH, Kim HL, et al. Presurgical sunitinib reduces tumor size and may facilitate partial nephrectomy in patients with renal cell carcinoma. Urol Oncol 2015; 33: 112.e115-121.

110. Sternberg CN, Calabro F, Bracarda S, et al. Safety and efficacy of sunitinib in patients from Italy with metastatic renal cell carcino- ma: final results from an expanded-access trial. Oncology 2015; 88: 273-80.

111. Rini BI, Quinn DI, Baum M, et al. Hypertension among patients with renal cell carcinoma receiving axitinib or sorafenib: analysis from the randomized phase III AXIS trial. Target Oncol 2015; 10: 45-53.

112. Rini BI, Escudier B, Hariharan S et al. Long-Term safety with axitinib in previously treated patients with metastatic renal cell carcinoma. Clin Genitourin Cancer 2015; 13: 540-47.e541-7.

113. Karam JA, Devine CE, Fellman BM et al. Variability of inter-observer agreement on feasibility of partial nephrectomy before and after neoadjuvant axitinib for locally advanced renal cell carcinoma (RCC): independent analysis from a phase II trial. BJU Int 2016; 117: 629-35.

114. Trask PC, Bushmakin AG, Cappelleri JC et al. Health-related quality of life during treatment for renal cell carcinoma: results from a phase II study of axitinib. Acta Oncol 2008; 47: 843-51.

115. Mendel DB, Laird AD, Xin X, et al. In vivo antitumor activity of SU11248, a novel tyrosine kinase inhibitor targeting vascular endothelial growth factor and platelet-derived growth factor receptors: determination of a pharmacokinetic/pharmacodynamic relationship. Clin Cancer Res 2003; 9: 327-37.

116. Kwilas AR, Donahue RN, Tsang KY, Hodge JW. Immune consequences of tyrosine kinase inhibitors that synergize with cancer immunotherapy. Cancer Cell Microenviron 2015; 2: pii: e677.

117. Farsaci B, Donahue RN, Coplin MA, et al. Immune consequences of decreasing tumor vasculature with antiangiogenic tyrosine kinase inhibitors in combination with therapeutic vaccines. Cancer Immunol Res 2014; 2: 1090-102.

118. Stehle F, Schulz K, Fahldieck C, et al. Reduced immunosuppressive properties of axitinib in comparison with other tyrosine kinase inhibitors. J Biol Chem 2013; 288: 16334-47.

119. Salas RN, Finke JH, Rini BI. The intersection of sunitinib with the immunosuppressive microenvironment of renal cell carcinoma: implications for future therapeutics. Targeted Oncology 2007; 2: 225-34.

120. Adotevi O, Pere H, Ravel P, et al. A decrease of regulatory T cells correlates with overall survival after sunitinib-based antiangiogenic therapy in metastatic renal cancer patients. I Immunother 2010; 33: 991-8.

121. Finke JH, Rini B, Ireland J, et al. Sunitinib reverses type-1 immune suppression and decreases T-regulatory cells in renal cell carcinoma patients. Clinical Cancer Research 2008; 14: 6674-82.

122. Finke J, Ko J, Rini B, et al. MDSC as a mechanism of tumor escape from sunitinib mediated anti-angiogenic therapy. Int Immunopharmacol 2011; 11: 856-61.

123. Xin H, Zhang C, Herrmann A, et al. Sunitinib inhibition of Stat3 induces renal cell carcinoma tumor cell apoptosis and reduces immunosuppressive cells. Cancer Res 2009; 69: 2506-13.

124. George S, Rayman P, Biswas S, et al. Expression of FLT3 and VEGFR1 on myeloid derived suppressor cells (MDSC) in renal cell carcinoma (RCC) patients (Pts). ASCO Meeting Abstracts 2008; 26: 5108.

125. Ko JS, Rayman P, Ireland J, et al. Direct and differential suppression of myeloid-derived suppressor cell subsets by sunitinib is compartmentally constrained. Cancer Res 2010; 70: 3526-36.

126. van Cruijsen $\mathrm{H}$, van der Veldt AAM, Vroling L, et al. Sunitinib-Induced Myeloid Lineage Redistribution in Renal Cell Cancer Patients: CD1c+ Dendritic Cell Frequency Predicts Progression-Free Survival. Clin Cancer Res 2008; 14: 5884-92.

127. Bex A, Etto T, Vyth-Dreese F, et al. Immunological Heterogeneity of the RCC Microenvironment: Do Targeted Therapies Influence Immune Response? Curr Oncol Rep 2012; 14: 230-9.

128. Hipp MM, Hilf N, Walter S, et al. Sorafenib, but not sunitinib, affects function of dendritic cells and induction of primary immune responses. Blood 2008; 111: 5610-20.

129. Zhao W, Gu YH, Song R, et al. Sorafenib inhibits activation of human peripheral blood T cells by targeting LCK phosphorylation. Leukemia 2008; 22: 1226-33.

130. Desar IME, Jacobs JHFM, Hulsbergen-vandeKaa Ca, et al. Sorafenib reduces the percentage of tumour infiltrating regulatory $T$ cells in renal cell carcinoma patients. International journal of cancer. Int J Cancer 2011; 129: 507-12. 
131. Flörcken A, Takvorian A, Van Lessen A, et al. Sorafenib, but not sunitinib, induces regulatory $T$ cells in the peripheral blood of patients with metastatic renal cell carcinoma. Anti-Cancer Drugs 2012; 23: 298-302.

132. Busse A, Asemissen AM, Nonnenmacher A, et al. Immunomodulatory effects of sorafenib on peripheral immune effector cells in metastatic renal cell carcinoma. Eur J Cancer 2011; 47: 690-6.

133. Santoni M, Berardi R, Amantini C, et al. Role of natural and adap tive immunity in renal cell carcinoma response to VEGFR-TKIs and mTOR inhibitor. Int J Cancer 2014; 134: 2772-7.

134. Porta C, Paglino C, Grünwald V. Sunitinib re-challenge in advanced renal-cell carcinoma. Br J Cancer 2014; 111: 1047-53.

135. Chen YF, Fu LW. Mechanisms of acquired resistance to tyrosine kinase inhibitors. Acta Pharmaceutica Sinica B 2011; 1: 197-207.

136. Sato Y. Persistent vascular normalization as an alternative goal of anti-angiogenic cancer therapy. Cancer Sci 2011; 102: 1253-6.

137. Kieda C, Greferath R, Crola Da Silva C, Fylaktakidou KC, Lehn JM, Nicolau C. Suppression of hypoxia-induced HIF-1 and of angiogenesis in endothelial cells by myo-inositol trispyrophosphate-treated erythrocytes. Proc Natl Acad Sci U S A 2006; 103: 15576-81.

138. Kieda C, El Hafny-Rahbi B, Collet G, et al. Stable tumor vessel normalization with $\mathrm{pO} 2$ increase and endothelial PTEN activation by inositol trispyrophosphate brings novel tumor treatment. J Mol Med 2013; 91: 883-99.

139. Collet G, Lamerant-Fayel N, Tertil M, et al. Hypoxia-regulated overexpression of soluble VEGFR2 controls angiogenesis and inhibits tumor growth. Mol Cancer Ther 2014; 13: 165-78.

\section{Address for correspondence}

Klaudia K. Brodaczewska

Laboratory of Molecular Oncology

Military Institute of Medicine

Szaserów 128

Warsaw, Poland

e-mail: kbrodaczewska@wim.mil.pl 